\title{
CJEM and pharmaceutical advertisements: it's time for an end
}

\author{
Joel Lexchin, MD
}

VERSION FRANÇAISE À LA PAge $\mathbf{3 8 0}$

\section{BACKGROUND}

Pharmaceutical advertisements in medical journals have repeatedly been criticized for their influence on physicians and, ultimately, their effect on prescription practices. ${ }^{1}$ Specifically, advertisements manipulate or bias their message using various techniques:

- presenting their information in certain ways in graphs ${ }^{2}$

- presenting benefits as relative rather than absolute risk reductions or numbers needed to treat ${ }^{3,4}$

- omitting confidence intervals and power calculations $s^{5,6}$

- making unsubstantiated claims about clinical or economic efficacy and quality-of-life benefits ${ }^{4,6-8}$

- failing to provide key messages required for guidelineconcordant care ${ }^{9}$

- using poor-quality references ${ }^{10,11}$

Doctors claim to have a negative viewpoint about the educational value of advertisements ${ }^{12}$ and report they do not use advertisements as a source of information. ${ }^{13,14}$ However, despite these statements, there is little doubt of the success of advertising on influencing physicians. ${ }^{15,16}$ Advertisements target the newest and most expensive products contributing to the increase in prescription drug spending, ${ }^{17}$ thereby diverting financial resources from other areas of health care. Extensive advertising of new drugs also leads to widespread use before adequate safety information is available; this may have serious safety consequences, such as those seen with rofecoxib (Vioxx).

Not only are journal advertisements successful in increasing sales, and therefore prescriptions, there is also some evidence that physicians who use journal advertisements as sources of information prescribe less appropriately. ${ }^{18,19}$
Journals justify running advertisements because of the income generated. This revenue can be used to build the journal and reduce subscription rates. ${ }^{20}$ Richard Smith, former editor of the $B M J$, argues that carrying advertisements helps to diversify the revenue sources for journals and thereby contributes to their financial independence. ${ }^{21}$ Some societies generate more money from journal advertisements than they do from membership fees, which raises the prospect of serious potential conflicts of interest $\mathrm{t}^{22}$ and possibly undermines the public's confidence in the independence of the medical advice that these societies give.

In light of the biases in journal advertisements, the possible negative effects that they may have on doctors' prescribing habits, their contribution to rising drug costs and the potential threat that they pose to the independence of medical societies, CJEM should refuse all advertisements for pharmaceutical products. Can the Canadian Association of Emergency Physicians (CAEP), which owns CJEM, take this step and survive financially?

\section{REVENUE FROM PHARMACEUTICAL ADVERTISEMENTS}

To estimate the revenue from pharmaceutical advertisements, the 24 issues of CJEM from January 2005 to November 2008 were hand searched and all advertisements were identified. Based on the rate cards for each year (the charges for different types of advertisements) the revenue from both pharmaceutical and all other types of advertisements was calculated per issue and for the entire year. (No adjustments were made for inflation.)

Table 1 shows the estimated advertising revenue per issue and for each year. Median revenue per issue from

Professor, School of Health Policy and Management, York University, Toronto, Ont.; Active Staff, Emergency Department, University Health Network, Toronto, Ont.; Associate Professor, Department of Family and Community Medicine, University of Toronto, Toronto, Ont.

All editorial matter represents the views of the authors and not necessarily those of CJEM or the Canadian Association of Emergency Physicians. 
pharmaceutical companies was Can\$14 472 (with a range of $\$ 5828$ to $\$ 26110$ ); median revenue from other advertisements was $\$ 10832$ (ranging from $\$ 4590$ to $\$ 18$ 126). In 6 of the 24 issues more revenue was generated from other advertising than from pharmaceutical advertising.

\section{REPLACEMENT SOURCES OF REVENUE}

To remain revenue neutral, CAEP would have to replace pharmaceutical advertisement income with funds from other sources. Membership fees for active CAEP members would have to increase by $\$ 47$ to $\$ 113$ or from as little as $13 \%$ to a maximum of $32 \%$, if this were the only source of alternative funding (Table 2).

Such a change in membership fees is an estimate based on historical trends in advertising revenue and may have to be revisited in the future. Advertising revenue can vary significantly (Table 1) and is difficult to predict, with many factors from the economy in general, and the pharmaceutical industry in particular, contributing to the uncertainty. Income is also affected by the variables influencing production costs, including the price of

\begin{tabular}{|c|c|c|c|c|}
\hline Variable & 2005 & 2006 & 2007 & 2008 \\
\hline $\begin{array}{l}\text { No. of active } \\
\text { members }\end{array}$ & 1389 & 1230 & 1149 & 1185 \\
\hline Fee, $\$$ & 335 & 345 & 355 & 365 \\
\hline $\begin{array}{l}\text { Additional fee } \\
\text { required to replace } \\
\text { advertising revenue, } \\
\$(\% \text { increase) }\end{array}$ & $47(14)$ & $63(18)$ & $113(32)$ & 55 (15) \\
\hline
\end{tabular}

Table 1. Number of pages of advertisements and revenue* per CJEM issue, 2005-2008

\begin{tabular}{|c|c|c|c|c|c|}
\hline \multirow[b]{2}{*}{ Issue } & \multirow{2}{*}{$\begin{array}{c}\text { Total no. of } \\
\text { pages/issue } \\
\text { (including covers) }\end{array}$} & \multicolumn{2}{|c|}{ Pharmaceutical advertisements } & \multicolumn{2}{|c|}{ Other advertisements } \\
\hline & & No. of pages & Revenue, $\$$ & No. of pages & Revenue, \$ \\
\hline January 2005 & 76 & $10 \%$ & 19678 & $2 \%$ & 4590 \\
\hline March 2005 & 74 & 6 & 13086 & $2 \frac{1}{2}$ & 5859 \\
\hline May 2005 & 74 & 3 & 5828 & $5 \%$ & 9085 \\
\hline July 2005 & 76 & 3 & 5828 & $6 \frac{1}{2}$ & 12578 \\
\hline September 2005 & 76 & 6 & 10958 & $4 \frac{1}{2}$ & 8220 \\
\hline November 2005 & 76 & $4 \frac{1}{2}$ & 9693 & $43_{4}^{3}$ & 9345 \\
\hline January 2006 & 76 & $63^{3} / 4$ & 12195 & $4 \frac{1}{4}$ & 9901 \\
\hline March 2006 & 76 & $10 \%$ & 20609 & $3 \frac{2}{3}$ & 8876 \\
\hline May 2006 & 100 & $43_{4}^{3}$ & 10095 & $4 \%_{12}$ & 10080 \\
\hline July 2006 & 76 & $3 \frac{3}{4}$ & 6995 & $4 \frac{2}{3}$ & 7650 \\
\hline September 2006 & 76 & $9 \%$ & 15339 & $3{ }^{17} / 24$ & 7760 \\
\hline November 2006 & 76 & $6 \frac{3}{4}$ & 12195 & $4 \%$ & 9551 \\
\hline January 2007 & 76 & $4 \frac{1}{2}$ & 8080 & $7 \%$ & 15688 \\
\hline March 2007 & 84 & $15 \%$ & 21160 & $2 \%$ & 6020 \\
\hline May 2007 & 100 & $123_{4}^{3}$ & 25725 & $6 \%$ & 12740 \\
\hline July 2007 & 92 & $13 \%$ & 26013 & $6^{17} / 24$ & 16440 \\
\hline September 2007 & 84 & $12 \%$ & 22578 & $5 \frac{1}{2}$ & 12693 \\
\hline November 2007 & 100 & $13 \frac{1}{2}$ & 26110 & $7 \frac{1}{3}$ & 16498 \\
\hline January 2008 & 100 & $4 \%$ & 9734 & $3 \%$ & 8996 \\
\hline March 2008 & 100 & $5 \frac{1}{3}$ & 10663 & $7 \%$ & 18126 \\
\hline May 2008 & 124 & 5 & 8443 & $6 \%$ & 14611 \\
\hline July 2008 & 100 & 9 & 17305 & $5 \%$ & 11960 \\
\hline September 2008 & 100 & 8 & 15106 & $4 \frac{3}{4}$ & 10006 \\
\hline November 2008 & 100 & $5 \%$ & 13929 & $4 \%_{12}^{7}$ & 12705 \\
\hline 2005 total & & $32 \%$ & 65071 & $2511 / 12$ & 49677 \\
\hline 2006 total & & $42 \%$ & 77428 & $25{ }^{7} / 2$ & 53818 \\
\hline 2007 total & & $71^{3} / 4$ & 129666 & $36 \%$ & 80079 \\
\hline 2008 total & & $38 \frac{1}{3}$ & 65446 & $32 \frac{7}{24}$ & 64417 \\
\hline
\end{tabular}


paper, postal rates, staff salaries and whether or not CJEM continues to qualify for the Canada Magazine Fund.

There are also other sources of revenue that could be explored. Institutional subscription rates could be raised, although it is not known how increases might affect the willingness of libraries to subscribe to the journal, and general revenue from this source is already declining. Annual revenue from other types of advertising ranges from $62 \%$ to $98 \%$ (calculated from figures in Table 1) of that received from pharmaceutical products; and this amount could be increased by systematically targeting alternative advertisers who may be eager to reach a market with relatively large amounts of disposable income. ${ }^{23}$

\section{OTHER ARGUMENTS FOR RETAINING PHARMACEUTICAL ADVERTISING}

Beyond the question of revenue from advertisements, there are a number of rationales that could be advanced for continuing to run advertisements for pharmaceutical products. However, under close scrutiny none of them are particularly compelling.

\section{Canadian control of advertising is adequate}

There are very few studies about Canadian advertisements identifying problems. Some might argue that because virtually all advertisements appearing in Canadian medical journals are prescreened by the Pharmaceutical Advertising Advisory Board (PAAB), ${ }^{24}$ the quality of Canadian advertisements is superior to those in other countries. The PAAB Code does have some very positive features, such as requiring advertisers to report either absolute risk reductions or numbers needed to treat; however, to date there have not been any comparative studies of the quality of Canadian journal advertising.

Furthermore, the PAAB Code also has serious limitations. Information about a product is not contiguous with the display portion of the advertisement, and is therefore placed at the back of the journal; the type size for the generic name of the product is significantly smaller than that for the brand name; and companies are allowed to present claims about a product in large print and then in small print at the bottom of the page state that the clinical significance of these claims has not been determined. Should an advertisement be found to have breached the PAAB Code there are no financial penalties, and other penalties such as corrective letters have been used only in very rare instances.

\section{Advertising has not caused CJEM to change its editorial policy}

There are no publicly known instances in which companies advertising in CJEM have tried to influence the content of the journal, but that does appear to have happened elsewhere. ${ }^{25}$ In addition, when one journal published an article unfavourable to the pharmaceutical industry the companies took revenge on the journal by withdrawing advertising. ${ }^{20} \mathrm{~A}$ related argument is that if CJEM stops running advertisements, then companies may respond by withdrawing support from CAEP activities. This is a contingency that CAEP should plan for, but this is not an excuse to continue to run pharmaceutical advertisements.

\section{Pharmaceutical advertisements shouldn't be singled out}

It could also be argued that if advertisements for pharmaceutical products are not allowed, then the same should apply to advertisements for medical devices, since inappropriate choice of a device could also have negative consequences for patient care. Although this is true, there are significant differences between devices and drugs as used by emergency physicians. Unlike medications, doctors have the opportunity to trial medical devices before they actually use them on patients and can directly look for design weaknesses or other problems. Moreover, devices are used almost exclusively in the emergency department, where patients can be closely monitored, whereas patients are frequently sent home into a relatively unmonitored environment with prescriptions. Although there are societal costs for inappropriate use of both pharmaceutical products and medical devices, patients may bear the economic cost of inappropriate prescriptions directly if they pay out-of-pocket or indirectly if private insurance premiums increase, but they rarely pay directly for medical devices.

\section{Why should CJEM be different from other journals?}

Finally, there is the argument that all other journals accept pharmaceutical advertising. Some online journals such as Open Medicine and PLoS Medicine do not accept pharmaceutical advertisements. Before it folded, the Western Journal of Medicine, a print publication, did not take pharmaceutical advertisements and currently the print version of the Journal of General Internal Medicine does not run pharmaceutical advertisements. 
ARE THERE ALTERNATIVES TO BANNING PHARMACEUTICAL ADVERTISEMENTS?

Occasionally there have been suggestions that journal editors screen advertisements before allowing them to appear, but this is highly unrealistic. Editors do not have the necessary training to evaluate advertisements and, even if they did, they do not have the time, especially at small journals such as CJEM.

If doctors received better training in detecting biases in medical evidence, including advertisements, then journals could continue to accept the advertisements and they would not have any negative effects on physicians. However, that is no guarantee that they would become resistant to the message in advertisements. ${ }^{26} \mathrm{In}$ addition, if that actually happened, then in all likelihood companies would simply stop advertising.

\section{CONCLUSION}

There are multiple biases in pharmaceutical advertisements and there is some evidence that these advertisements may have a negative effect on prescribing behaviour. Other reasons, besides revenue generation, for continuing to accept pharmaceutical product advertising cannot be justified. Income from this source of advertising could be replaced by raising membership fees for active members, by exploring alternative sources of advertising or both.

Our current economic crisis once again provides further compelling evidence that private maximization of profit necessarily endangers the public good. Game theory suggests that resolving problems of this sort "require[s] a fundamental extension in morality." 27 The pharmaceutical industry operates within a profitoriented system and within that paradigm has delivered valuable medications, but has also been guilty of egregious excesses. If we are asking the industry to reform then we as doctors must do the same and change the way that we relate to the industry. The CAEP executive and membership should make the decision to end advertisements for pharmaceutical products in CJEM.

Competing interests: Dr. Lexchin was retained by a law firm representing Apotex to provide expert testimony about the effects of promotion on the sales of medications. Dr. Lexchin is retained as an expert witness by the Canadian federal government in its defence of a lawsuit challenging the ban on direct-toconsumer advertising of prescription drugs in Canada.

Keywords: journal advertising, pharmaceutical industry, prescribing, revenue

\section{REFERENCES}

1. Wilkes MS, Doblin BH, Shapiro MF. Pharmaceutical advertisements in leading medical journals: experts' assessments. Ann Intern Med 1992;116:912-9.

2. Cooper RJ, Schriger DL, Wallace RC, et al. Graphics in pharmaceutical advertisements: Are they truthful, are they adequately detailed? Plenary session at the Fourth International Congress on Peer Review in Biomedical Publication; 2001 Sep. 14-16; Barcelona (Spain): JAMA and BMJ Publishing Group; 2001. Available: www.ama-assn.org/public/peer /prc_program2001.htm\#truthful (accessed 2009 May 15).

3. Lexchin J. How patient outcomes are reported in drug advertisements: review of Canadian medical journals. Can Fam Physician 1999;45:1213-6.

4. Loke TW, Koh FC, Ward JE. Pharmaceutical advertisement claims in Australian medical publications: Is evidence accessible, compelling and communicated comprehensively? Med J Aust 2002;177:291-3.

5. Gutknecht DR. Evidence-based advertising? A survey of four major journals. J Am Board Fam Pract 2001;14:197-200.

6. Lankinen KS, Levola T, Marttinen K, et al. Industry guidelines, laws and regulations ignored: quality of drug advertising in medical journals. Pharmacoepidemiol Drug Saf 2004;13: $789-95$

7. Neumann PJ, Bambauer KZ, Ramakrishnan V, et al. Economic messages in prescription drug advertisements in medical journals. Med Care 2002;40:840-5.

8. Spielmans GI, Thielges SA, Dent AL, et al. The accuracy of psychiatric medication advertisements in medical journals. 7 Nerv Ment Dis 2008;196:267-73.

9. Montgomery BD, Mansfield PR, Spurling GK, et al. Do advertisements for antihypertensive drugs in Australia promote quality prescribing? A cross-sectional study. BMC Public Health 2008;8:167.

10. Cooper RJ, Schriger DL. The availability of references and the sponsorship of original research cited in pharmaceutical advertisements. CMAJ 2005;172:487-91.

11. Lexchin J, Holbrook A. Methodologic quality and relevance of references in pharmaceutical advertisements in a Canadian medical journal. CMAJ 1994;151:47-54.

12. Hemeryck L, Chan R, McCormack PME, et al. Pharmaceutical advertisements in Irish medical journals. 7 Pharm Med. 1995;5:147-51.

13. McGettigan P, Golden J, Fryer J, et al. Prescribers prefer people: the sources of information used by doctors for prescribing suggest that the medium is more important than the message. Br J Clin Pharmacol 2001;51:184-9.

14. Prosser H, Almond S, Walley T. Influences on GPs' decision to prescribe new drugs - the importance of who says what. Fam Pract 2003;20:61-8.

15. Avorn J, Chen M, Hartley R. Scientific versus commercial sources of influence on the prescribing behavior of physicians. Am J Med 1982;73:4-8.

16. Greenwood J. Pharmaceutical representatives and the prescribing of drugs by family doctors [dissertation]. Nottingham (UK): Nottingham University; 1989.

17. Findlay S. Prescription drugs and mass media advertising. 
Washington (DC): National Institute for Health Care Management Research and Educational Foundation; 2000.

18. Bower AD, Burkett GL. Family physicians and generic drugs: a study of recognition, information sources, prescribing attitudes and practices. 7 Fam Pract 1987;24:612-6.

19. Ferry ME, Lamy PP, Becker LA. Physicians' knowledge of prescribing for the elderly: a study of primary care physicians in Pennsylvania. I Am Geriatr Soc 1985;33:616-21.

20. Fletcher RH. Adverts in medical journals: caveat lector. Lancet 2003;361:10-1.

21. Smith R. Should medical journals carry drug advertising? BMJ 2007;335:74.

22. Glassman PA, Hunter-Hayes J, Nakamura T. Pharmaceutical advertising revenue and physician organizations: How much is too much? West J Med 1999;171:234-8.

23. Fugh-Berman A, Alladin K, Chow J. Advertising in medical journals: Should current practices change? PLoS Med 2006; 3:e130.

24. Pharmaceutical Advertising Advisory Board. Code of advertising acceptance. Pickering (ON): The Board; 2007.

25. Lexchin J, Light D. Commercial influence and the content of medical journals. BMJ 2006;332:1444-7.

26. Mansfield PR, Lexchin J, Wen LS, et al. Educating health professionals about drug and device promotion: advocates' recommendations. PLoS Med 2006;3:e451.

27. Hardin G. The tragedy of the commons. Science 1968;162: 1243-8.

Correspondence to: Dr. Joel Lexchin, School of Health Policy and Management, York University, 4700 Keele St., Toronto ON M3J 1P3; jlexchin@yorku.ca

\section{Change of address}

We require 6 to 8 weeks' notice to ensure uninterrupted service. Please send your current mailing label, new address and the effective date of change to:

\section{Canadian Association of Emergency Physicians}
104-1785 Alta Vista Dr.
Ottawa ON K1G 3 Y6
613 523-3343
fax $613523-0190$
admin@caep.ca

\section{Changement d'adresse}

II nous faut de 6 à 8 semaines d'avis afin de vous assurer une livraison ininterrompue. Veuillez faire parvenir votre étiquette d'adresse actuelle, votre nouvelle adresse et la date de la prise d'effet du changement, à l'attention du

\section{Association canadienne des médecins d'urgence}

104-1785, prom. Alta Vista

Ottawa ON K1G 3 Y6

613 523-3343

fax 613 523-0190

admin@caep.ca 